\title{
Simulated Sunlight Induced the Degradation of Rhodamine B Over Graphene Oxide-Based $\mathrm{Ag}_{3} \mathrm{PO}_{4} @ \mathrm{AgCl}$
}

\author{
Mahgoub Ibrahim Shinger ${ }^{1,2}$, Ahmed Mahmoud Idris ${ }^{1}$, Dong Dong Qin ${ }^{1}$, Hind Baballa ${ }^{1}$, \\ Duoliang Shan ${ }^{1}$, Xiaoquan $\mathrm{Lu}^{1, *}$
}

${ }^{1}$ Key Laboratory of Bioelectrochemistry \& Environmental Analysis of Gansu Province, College of Chemistry \& Chemical Engineering, Northwest Normal University, Lanzhou, China

${ }^{2}$ Chemistry Department, Faculty of Science, International University of Africa, Khartoum, Sudan

\section{Email address:}

shinger1977@yahoo.com (M. I. Shinger), ahmedwadmahmoud@yahoo.com (A. M. Idris), 395148255@qq.com (Dong Dong Qin), hindfnc@hotmail.com (H. Baballa), shandouliang@126.com (Duoliang Shan), luxq@nwnu.edu.cn (Xiaoquan Lu)

\section{To cite this article:}

Mahgoub Ibrahim Shinger, Ahmed Mahmoud Idris, Dong Dong Qin, Hind Baballa, Duoliang Shan, Xiaoquan Lu. Simulated Sunlight Induced the Degradation of Rhodamine B Over Graphene Oxide-Based $\mathrm{Ag}_{3} \mathrm{PO}_{4} @ \mathrm{AgCl}$. International Journal of Materials Science and Applications. Vol. 4, No. 4, 2015, pp. 246-255. doi: 10.11648/j.ijmsa.20150404.14

\begin{abstract}
A facile, environmentally friendly and economical in-situ ion-exchange method was successfully fabricated graphene oxide-based $\mathrm{Ag}_{3} \mathrm{PO}_{4} @ \mathrm{AgCl}$ photocatalyst to promote the photocatalytic activity of $\mathrm{Ag}_{3} \mathrm{PO}_{4} @ \mathrm{AgCl}$. The as synthesized GO- $\mathrm{Ag}_{3} \mathrm{PO}_{4} @ \mathrm{AgCl}$ composite was characterized by Fourier transform infrared (FTIR), X-ray diffraction (XRD), $\mathrm{UV}$-vis diffuse reflectance spectroscopy and photoluminescence (PL). The morphology and the structure of the synthesized photocatalyst were characterized by field-emission scanning electron microscopy (SEM) and transmitter electron microscopy (TEM). The elements detection and the chemical state of the sample were investigated by X-ray photoelectron spectroscopy (XPS) analysis. GO- $\mathrm{Ag}_{3} \mathrm{PO}_{4} @ \mathrm{AgCl}$ exhibited higher photocatalytic activity over $\mathrm{Ag}_{3} \mathrm{PO}_{4} @ \mathrm{AgCl}$ and $\mathrm{Ag}_{3} \mathrm{PO}_{4}$ for the degradation of Rhodamine $\mathrm{B}(\mathrm{RhB})$ under simulated sunlight, and the highest photocatalytic activity was obtained by $\mathrm{GO}-\mathrm{Ag}_{3} \mathrm{PO}_{4} @ \mathrm{AgCl}$ photocatalyst with $\mathrm{Cl} / \mathrm{P}$ ratio of 0.5 . The quenching study using different scavengers investigated that the photogenerated holes $\left(\mathrm{h}^{+}\right)$and superoxide radicals $\left({ }^{\circ} \mathrm{O}_{2}^{-}\right)$played a key role in the degradation of $\mathrm{RhB}$. The kinetic study revealed that the degradation of $\mathrm{RhB}$ over $\mathrm{GO}-\mathrm{Ag}_{3} \mathrm{PO}_{4} @ \mathrm{AgCl}-0.5$ under simulated sunlight followed the first-order kinetics.
\end{abstract}

Keywords: $\mathrm{GO}, \mathrm{Ag}_{3} \mathrm{PO}_{4}, \mathrm{AgCl}, \mathrm{RhB}$ and Simulated Sunlight Irradiation

\section{Introduction}

Photocatalysts as a new branch used as organic pollutant removal from wastewater have attracted considerable attention because of their potential applications for removal and degradation of organic dyes which falls as the largest group of water pollutants for their toxicity and carcinogenicity [1-3]. Recently Silver orthophosphate $\mathrm{Ag}_{3} \mathrm{PO}_{4}$ has been reported as a new visible light-driven photocatalyst with high photocatalytic performance for the oxygen evaluation from water and the photodecomposition of organic dyes under visible light irradiation [4-7]. But, $\mathrm{Ag}_{3} \mathrm{PO}_{4}$ has disadvantages, such as high cost of the starting material $\mathrm{AgNO}_{3}$, and decomposing to weakly active $\mathrm{Ag}$ during the photocatalytic reaction process. Moreover, the irregular polyhedral microstructure of $\mathrm{Ag}_{3} \mathrm{PO}_{4}$ has poor dispersity/stability due to its slight solubility in aqueous solution [8]. As a result, more attention has been paid to investigate new $\mathrm{Ag}_{3} \mathrm{PO}_{4}$ photocatalyst systems with good structural, catalytic activity and stability. Thus, many studies have been synthesized $\mathrm{Ag}_{3} \mathrm{PO}_{4}$-based composites including $\mathrm{Ag} / \mathrm{Ag}_{3} \mathrm{PO}_{4}$ [9], $\mathrm{TiO}_{2} / \mathrm{Ag}_{3} \mathrm{PO}_{4}$ [10], $\mathrm{Ag}_{3} \mathrm{PO}_{4} / \mathrm{ZnO}$ [11] and $\mathrm{SnO}_{2} / \mathrm{Ag}_{3} \mathrm{PO}_{4}$ [12]. In addition, the epitaxial growth of an $\mathrm{AgX}(\mathrm{X}=\mathrm{Cl}, \mathrm{Br}$ and $\mathrm{I})$ on the surface of $\mathrm{Ag}_{3} \mathrm{PO}_{4}$ could greatly enhance the chemical stability and activity of $\mathrm{Ag}_{3} \mathrm{PO}_{4}$ [13]. Recently, graphene oxide (GO) has become an ideal support for the photocatalysts, because of possessing two dimensional structures and large specific surface area may tailor the size and morphology of photocatalysts. Therefore, the cost for the synthesis of $\mathrm{Ag}_{3} \mathrm{PO}_{4}$-based photocatalysts can be greatly reduced. Moreover GO has conductive properties that give it excellent mobility of charge carriers, and high chemical and thermal stability [14-17]. Therefore, it is expected that the fabrication of graphene with $\mathrm{Ag}_{3} \mathrm{PO}_{4}$-based photocatalysts can greatly 
improve its photocatalytic activity and stability. Recently, many groups have reported graphene-based $\mathrm{Ag}_{3} \mathrm{PO}_{4}$ photocatalysts with enhanced photocatalytic activity, such as GO- $\mathrm{Ag}_{3} \mathrm{PO}_{4}[18,19]$ and GO- $\mathrm{Ag}_{3} \mathrm{PO}_{4} / \mathrm{Ag}[20,21]$. Therefore, the combination of graphene oxide, $\mathrm{Ag}_{3} \mathrm{PO}_{4}$ and $\mathrm{AgCl}$ may be regarded as a good photocatalytic system for achieving enhanced photocatalytic activity and stability.

According to our knowledge, till now, very few studies have reported the synthesis of $\mathrm{Ag}_{3} \mathrm{PO}_{4} @ \mathrm{AgCl}$ due to the wide band gap of $\mathrm{AgCl}$ (3.2 eV), and no previous studies regarding the photocatalytic activity of $\mathrm{GO}-\mathrm{Ag}_{3} \mathrm{PO}_{4} @ \mathrm{AgCl}$ under simulated sunlight have been reported. In this study we synthesized graphene-based $\mathrm{Ag}_{3} \mathrm{PO}_{4} @ \mathrm{AgCl}$ composite with enhanced photocatalytic activity via a simple in-situ ion-exchange method. Furthermore, we demonstrated that GO-based $\mathrm{Ag}_{3} \mathrm{PO}_{4} @ \mathrm{AgCl}$ exhibited the enhancement of the photocatalytic degradation of Rhodamine B (RhB) over $\mathrm{Ag}_{3} \mathrm{PO}_{4} @ \mathrm{AgCl}$ composite under simulated sunlight. In addition, prominently enhanced photocatalytic activity was carried out by comparing with $\mathrm{Ag}_{3} \mathrm{PO}_{4} @ \mathrm{AgCl}$ in the present study. Moreover, the effect of mass ratios of $\mathrm{AgCl}$ in the GO- $\mathrm{Ag}_{3} \mathrm{PO}_{4} @ \mathrm{AgCl}$ composites on the photocatalytic activity was also investigated comparatively.

\section{Experimental}

\subsection{Materials}

Chemicals used in this study all were of analytical grade used as reserved without further purification.

\subsection{Synthesis of Graphene}

Using modified Hummers method graphene oxide was prepared from natural graphite [22]. In a typical synthesis, 2.5 $\mathrm{g}$ of $\mathrm{K}_{2} \mathrm{~S}_{2} \mathrm{O}_{8}$ was added to $2.5 \mathrm{~g}$ of $\mathrm{P}_{2} \mathrm{O}_{8}$ in a round bottom flask and dissolved by $12 \mathrm{ml}$ of concentrated $\mathrm{H}_{2} \mathrm{SO}_{4}$ under stirring, followed by addition of $1 \mathrm{~g}$ of graphite and stirred for $30 \mathrm{~min}$. Then the temperature was elevated to $80{ }^{\circ} \mathrm{C}$ and the reactants were kept on it to $4 \mathrm{~h}$. After that cooled at room temperature and washed with distilled water several time until the $\mathrm{pH}$ of the solution reached 7 . Then centrifuged and the precipitate was dried under vacuum at $60{ }^{\circ} \mathrm{C}$ for $24 \mathrm{~h}$. Afterwards, $1 \mathrm{~g}$ of the dried precipitate was added to $36 \mathrm{ml}$ of concentrated $\mathrm{H}_{2} \mathrm{SO}_{4}$ that was precooled to $0{ }^{\circ} \mathrm{C}$ and then stirred for $30 \mathrm{~min}$ for homogenization. Then, $5 \mathrm{~g}$ of $\mathrm{KMnO}_{4}$ was slowly added to the contents and the temperature kept at less than $10{ }^{\circ} \mathrm{C}$ under stirring for $30 \mathrm{~min}$. Then the temperature was slowly increased to $35{ }^{\circ} \mathrm{C}$ and left to react overnight. $350 \mathrm{ml}$ of distilled water was added to the mixture followed by the addition of $5 \mathrm{ml}$ of $30 \% \mathrm{H}_{2} \mathrm{O}_{2}$ (the color changed to bright yellow) and stirred for $30 \mathrm{~min}$. The obtained $\mathrm{GO}$ was washed by $5 \% \mathrm{HCl}$ to remove metal ions followed by washing with distilled water several times until the $\mathrm{pH}$ of the solution reached 7. The obtained GO was then suspended in distilled water and ultrasonicated for 2 $\mathrm{h}$, then centrifuged at $1100 \mathrm{r} / \mathrm{min}$ for $25 \mathrm{~min}$, and the supernatant was removed and the GO was dried under vacuum at $60{ }^{\circ} \mathrm{C}$ for $24 \mathrm{~h}$.

\subsection{Synthesis of $\mathrm{GO}-\mathrm{Ag}_{3} \mathrm{PO}_{4} @ \mathrm{AgCl}$}

GO- $\mathrm{Ag}_{3} \mathrm{PO}_{4} @ \mathrm{AgCl}$ was prepared by an in situ-ion exchange method. To $50 \mathrm{mg}$ of $\mathrm{GO}$ suspended in $50 \mathrm{ml} \mathrm{H} \mathrm{H}_{2} \mathrm{O}$ and stirred for $6 \mathrm{~h}, 2.4 \mathrm{~g} / 20 \mathrm{ml}$ of $\mathrm{AgNO}_{3}$ was added and stirred under dark condition for $12 \mathrm{~h}$. Afterward, $1.152 \mathrm{~g} / 20 \mathrm{ml}$ of $\mathrm{Na}_{2} \mathrm{HPO}_{4}$ was added dropwise and the mixture kept stirred for $1 \mathrm{~h}$ followed by the dropwise addition of $20 \mathrm{ml}$ of $\mathrm{NaCl}$ with $\mathrm{Cl} / \mathrm{P}$ molar ratio of 0.3 . Then the mixture was stirred for $6 \mathrm{~h}$ under the same condition. GO- $\mathrm{Ag}_{3} \mathrm{PO}_{4} @ \mathrm{AgCl}$ particles were obtained by filtering of the precipitate followed by drying under vacuum at $60{ }^{\circ} \mathrm{C}$ for $24 \mathrm{~h}$. Varying the amount of $\mathrm{AgCl}$ by the addition of $\mathrm{NaCl}$ with $\mathrm{Cl} / \mathrm{P}$ molar ratio of $0.3,0.5$ and 0.7, different $\mathrm{GO}-\mathrm{Ag}_{3} \mathrm{PO}_{4} @ \mathrm{AgCl}$ photocatalysts were prepared, and defined as GO- $\mathrm{Ag}_{3} \mathrm{PO}_{4} @ \mathrm{AgCl}-0.3$, GO-Ag3PO4@AgCl-0.5 and GO-Ag $\mathrm{PO}_{4} @ \mathrm{AgCl}-0.7$ respectively. For the comparison, using the same method different photocatalysts were prepared, $\mathrm{Ag}_{3} \mathrm{PO}_{4} @ \mathrm{AgCl}$ was fabricated without the use of $\mathrm{GO}$ and pure $\mathrm{Ag}_{3} \mathrm{PO}_{4}$ was also synthesized without the use of any of $\mathrm{GO}$ and $\mathrm{NaCl}$.

\subsection{Material Characterization}

Characterization of the Photocatalysts. X-ray diffraction (XRD) measurements were carried out at room temperature using a BRUKER D8 ADVANCE X-ray powder diffractometer with $\mathrm{Cu}-\mathrm{K} \alpha$ radiation $\left(\lambda=1.5406^{\circ} \mathrm{A}\right)$ in the $2 \theta$ range of $10{ }^{\circ} \mathrm{C}$ to $80{ }^{\circ} \mathrm{C}$. The morphology and the composition were characterized using Scanning electron microscope (SEM) and a JSM-7001F (JEOL) transmission electron microscope (TEM). The UV-visible diffuse reflectance spectra were obtained by a Shimadzu UV2450 spectrophotometer. The Fourier transform infrared (FTIR) spectra of the samples were recorded on a Bruker Vertex 70 FT-IR spectrophotometer using the $\mathrm{KBr}$ method. The photoluminescence (PL) were measured at room temperature on a Varian Cary Eclipse fluorescence spectrophotometer with the excitation wavelength at $320 \mathrm{~nm}$. Detection of the elements and chemical state of the sample were investigated by X-ray photoelectron spectroscopy (XPS) analysis.

\subsection{Evaluation of Photocatalytic Activity}

The study of the photocatalytic activity of the synthesized photocatalysts was carried out using $\mathrm{RhB}$ solution at room temperature. Briefly, $25 \mathrm{mg}$ of the as prepared photocatalyst was mixed with $50 \mathrm{ml}$ of $\mathrm{RhB}(0.005 \mathrm{~g} / \mathrm{L})$ then sonicated for $10 \mathrm{~min}$ followed by stirring in dark condition for $30 \mathrm{~min}$ to establish adsorption-desorption equilibrium. Afterwards, the mixture was irradiated with simulated sunlight using a $350 \mathrm{~W}$ Xe lamp as light source. During the illumination, $3 \mathrm{ml}$ aliquots were collected at a given time interval, then centrifuged to remove the photocatalyst. The concentration of $\mathrm{RhB}$ solution was determined by UV-visible spectrophotometer at $553 \mathrm{~nm}$ [23].

In order to detect the active species during the photocatalytic reaction, p-benzoquinone (BZQ), disodium ethylenediaminetetraacetate $\left(\mathrm{Na}_{2}\right.$-EDTA) and tert-butanol were added in to the $\mathrm{RhB}$ solution dispersed with the 
GO- $\mathrm{Ag}_{3} \mathrm{PO}_{3} @ \mathrm{AgCl}-0.5$ to capture superoxide radical $\left({ }^{\circ} \mathrm{O}_{2}{ }^{-}\right)$, holes $\left(\mathrm{h}^{+}\right)$and hydroxide radical $(\mathrm{OH})$, respectively, followed by the photocatalytic activity test.

\section{Results and Discussion}

\subsection{FT-IR Analysis}

In order to confirm the fabrication of $\mathrm{Ag}_{3} \mathrm{PO}_{4}$ and $\mathrm{AgCl}$ with GO sheets in GO- $\mathrm{Ag}_{3} \mathrm{PO}_{4} @ \mathrm{AgCl}-0.5$ photocatalyst, their FT-IR together with that of $\mathrm{Ag}_{3} \mathrm{PO}_{4} @ \mathrm{AgCl}, \mathrm{Ag}_{3} \mathrm{PO}_{4}$ and GO sheets are measured [Figure 1(A)]. The spectrum of GO sheets is included peak at $3420 \mathrm{~cm}^{-1}$ which attributed to the stretching vibration mode of ${ }^{-} \mathrm{OH}$, the stretching vibration band of the $\mathrm{C}=\mathrm{O}$ carbonyl is appeared at about $1715 \mathrm{~cm}^{-1}$ (attributed to $\mathrm{COOH}$ groups), the peak at about $1640 \mathrm{~cm}^{-1}$ is attributed to the binding vibration of $\mathrm{OH}$, at $1390 \mathrm{~cm}^{-1}$ the peak of the tertiary $\mathrm{C}-\mathrm{OH}$ stretching vibration is appeared, and the broad peak band at around $1140 \mathrm{~cm}^{-1}$ is due to the absorption of the vibration band of epoxy and alkoxy groups [24,25]. For the spectrum of $\mathrm{Ag}_{3} \mathrm{PO}_{4}$, the peaks at 3420 and $1650 \mathrm{~cm}^{-1}$ are corresponded to the ${ }^{-} \mathrm{OH}$ stretching and binding vibrations of physically absorbed $\mathrm{H}_{2} \mathrm{O}$ molecules respectively. The peak at about $550 \mathrm{~cm}^{-1}$ is related to the $\mathrm{O}=\mathrm{P}-\mathrm{O}$ bending vibration, the peaks at about 850 and $995 \mathrm{~cm}^{-1}$ are attributed to the symmetric and asymmetric stretching vibrations of P-O-P rings respectively. At $1385 \mathrm{~cm}^{-1}$ the stretching vibration peak of $\mathrm{P}=\mathrm{O}$ is observed [25]. In the spectrum of GO- $\mathrm{Ag}_{3} \mathrm{PO}_{4} @ \mathrm{AgCl}-0.5$ and $\mathrm{Ag}_{3} \mathrm{PO}_{4} @ \mathrm{AgCl}$ composites, the characteristic bands for $\mathrm{Ag}_{3} \mathrm{PO}_{4}$ still remain, but the peak which attributed to the stretching vibration of the $\mathrm{P}-\mathrm{O}-\mathrm{P}$ group is shifted to 1017 and $1010 \mathrm{~cm}^{-1}$ in the spectrums of GO- $\mathrm{Ag}_{3} \mathrm{PO}_{4} @ \mathrm{AgCl}-0.5$ and $\mathrm{Ag}_{3} \mathrm{PO}_{4} @ \mathrm{AgCl}$ respectively compared with that of $\mathrm{Ag}_{3} \mathrm{PO}_{4}$ spectrum $\left(995 \mathrm{~cm}^{-1}\right)$. Nevertheless, the band intensity at $1385 \mathrm{~cm}^{-1}$ is became weakened. Moreover, a new absorption band is appeared at $1550 \mathrm{~cm}^{-1}$, which is attributed to the skeletal vibration of the graphene sheets [26], proving the presence of $\mathrm{GO}$ in the spectrum of $\mathrm{GO}-\mathrm{Ag}_{3} \mathrm{PO}_{4} @ \mathrm{AgCl}-0.5$ composites, suggesting the formation of GO- $\mathrm{Ag}_{3} \mathrm{PO}_{4} @ \mathrm{AgCl}-0.5$ from the interaction between $\mathrm{GO}, \mathrm{Ag}_{3} \mathrm{PO}_{4}$ and $\mathrm{AgCl}$.

\subsection{XRD Analysis}

The crystallographic structures of the as-obtained products are determined by X-ray diffraction (XRD) measurements. $\mathrm{Ag}_{3} \mathrm{PO}_{4}$ is a body-centered cubic structure, consists of isolated and regular $\mathrm{PO}_{4}$ tetrahedral $(\mathrm{P}-\mathrm{O}$ distance of $\sim 1.539 \AA)$ to form a body-centered cubic lattice, and six $\mathrm{Ag}^{+}$ions are distributed among 12 sites of the two-fold symmetry [27]. As shown in Figure 1(B), the XRD patterns of the as-synthesized composites show that all patterns marked with solid rhombus are matched very well with the standard data of $\mathrm{Ag}_{3} \mathrm{PO}_{4}$ (JCPDS No. 06-0505), which is consistent with the previous study [28]. For the pattern of $\mathrm{GO}-\mathrm{Ag}_{3} \mathrm{PO}_{4} @ \mathrm{AgCl}-0.5$ and $\mathrm{Ag}_{3} \mathrm{PO}_{4} @ \mathrm{AgCl}$, besides the peaks of $\mathrm{Ag}_{3} \mathrm{PO}_{4}$, the diffraction peaks of $\mathrm{AgCl}$ at 2 theta $=27.9^{\circ}, 32.3^{\circ}, 46.4^{\circ} 67.4^{\circ}$ and $76.78^{\circ}$ which are corresponding to the (111), (200), (220), (400) and (420) planes are also detected [29], confirming that $\mathrm{AgCl}$ is formed on the $\mathrm{Ag}_{3} \mathrm{PO}_{4}$ surface after the reaction with $\mathrm{NaCl}$. However, no diffraction peak of graphene is observed in the XRD pattern of GO- $\mathrm{Ag}_{3} \mathrm{PO}_{4} @ \mathrm{AgCl}-0.5$, which may be due to the low diffraction intensity of the GO in the sample [30] or may be due to the destruction of the regular stack of graphene sheets by the assembly of $\mathrm{Ag}_{3} \mathrm{PO}_{4}$ nanoparticles [31].

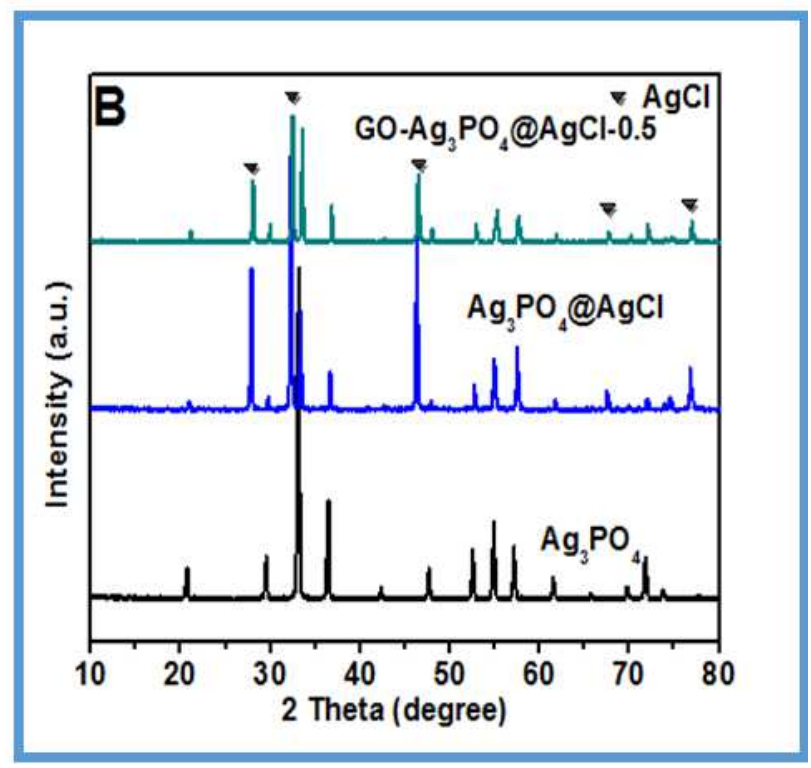

Figure 1. (A) FTIR spectrum of the synthesized photocatalysts. (B) XRD patterns of the synthesized photocatalyst

\subsection{SEM Analysis}

The morphology and structure of the synthesized samples are also characterized by field-emission scanning electron microscopy (SEM). It can be seen in Figure 2(A) that, $\mathrm{Ag}_{3} \mathrm{PO}_{4}$ possess an irregular sphere-like polyhedral morphology with an average diameter of $650 \mathrm{~nm}$. As shown in Figure 2(B), it is 
clearly seen that, $\mathrm{AgCl}$ is grown on the surface of $\mathrm{Ag}_{3} \mathrm{PO}_{4}$ to form $\mathrm{Ag}_{3} \mathrm{PO}_{4} @ \mathrm{AgCl}$ composite with heterogeneous structure with average diameters less than that of $\mathrm{Ag}_{3} \mathrm{PO}_{4}$ due to the interaction between two species. As in the SEM images in Figure 2(C), after the interaction between $\mathrm{GO}$ and $\mathrm{Ag}^{+}$ followed by the addition of $\mathrm{PO}_{4}{ }^{3-}$ and $\mathrm{Cl}^{-}$into this synthesis system, GO- $\mathrm{Ag}_{3} \mathrm{PO}_{4} @ \mathrm{AgCl}-0.5$ composites is obtained; in this process, first, the electrostatic properties drive the self-assembly of the positively charged $\mathrm{Ag}^{+}$and the negatively charged GO sheets, then, the $\mathrm{Ag}_{3} \mathrm{PO}_{4}$ particles are generated on the surface of $\mathrm{GO}$ sheets after the addition of $\mathrm{PO}_{4}{ }^{3-}$, afterward, $\mathrm{AgCl}$ particles are epitaxially grown on the surface of $\mathrm{Ag}_{3} \mathrm{PO}_{4}$, resulting on a large amount of $\mathrm{Ag}_{3} \mathrm{PO}_{4} @ \mathrm{AgCl}-0.5$ particles distributed on the surface of the flexible GO sheets. SEM observations imply that the presence of GO has a luminous effect on the morphology of $\mathrm{Ag}_{3} \mathrm{PO}_{4} @ \mathrm{AgCl}-0.5$ particles. As a result, the specific surface area is decreased, which might be a key reason for the enhanced photocatalytic
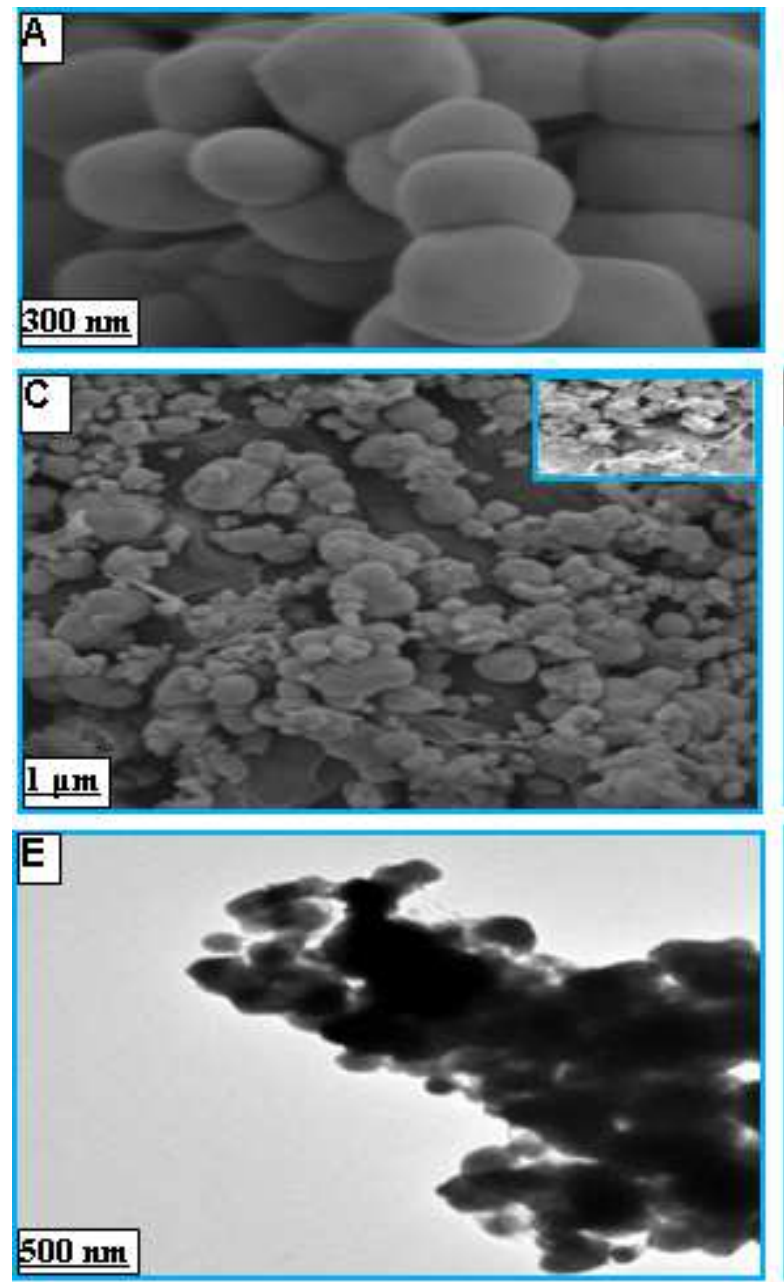

activity [32]. Moreover, the smaller size $\mathrm{Ag}_{3} \mathrm{PO}_{4} @ \mathrm{AgCl}$ of GO- $\mathrm{Ag}_{3} \mathrm{PO}_{4} @ \mathrm{AgCl}-0.5$ composites might supply enough contact surface area between the GO sheets and $\mathrm{Ag}_{3} \mathrm{PO}_{4} @ \mathrm{AgCl}$ particles which support the charge-carrier transport, contributing partially to the higher photocatalytic performance of the $\mathrm{GO}-\mathrm{Ag}_{3} \mathrm{PO}_{4} @ \mathrm{AgCl}-0.5$ composites [33].

\subsection{TEM Analysis}

Figure 2(D, E, and F) shows the TEM image of GO-Ag $\mathrm{PO}_{4} @ \mathrm{AgCl}-0.5, \quad \mathrm{Ag}_{3} \mathrm{PO}_{4} @ \mathrm{AgCl}$ and $\mathrm{Ag}_{3} \mathrm{PO}_{4}$ respectively. As seen clearly, all the results are in good agreement with that of SEM image. As a result, GO- $\mathrm{Ag}_{3} \mathrm{PO}_{4} @ \mathrm{AgCl}-0.5$ composite is successfully fabricated with $\mathrm{Ag}_{3} \mathrm{PO}_{4} @ \mathrm{AgCl}-0.5$ particle size less than that of $\mathrm{Ag}_{3} \mathrm{PO}_{4} @ \mathrm{AgCl}$, contributing to the best photocatalytic activity of GO-Ag $\mathrm{PO}_{4} @ \mathrm{AgCl}-0.5$ which would be discussed latter.
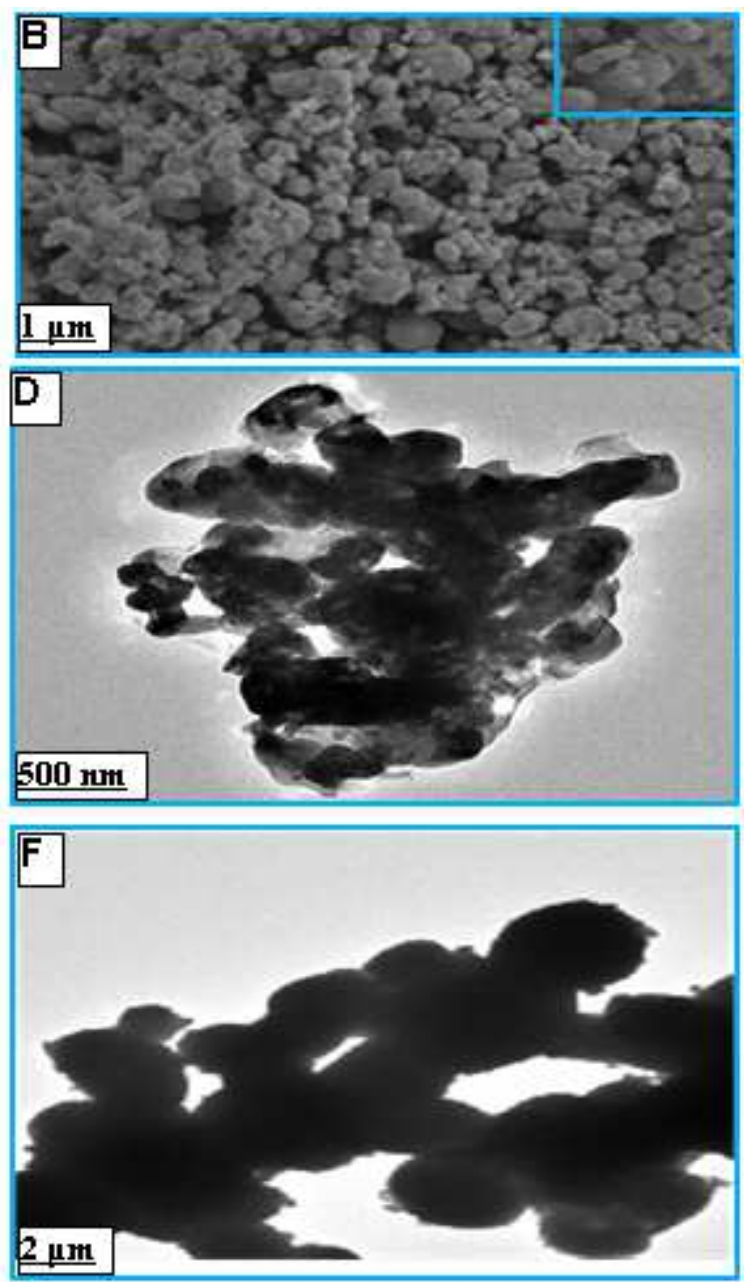

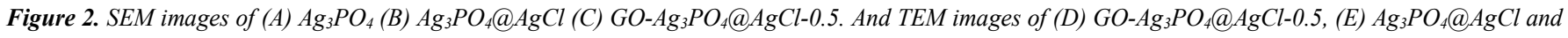
(F) $\mathrm{Ag}_{3} \mathrm{PO}_{4}$

\subsection{XPS Analysis}

The chemical composition and the valence state of the different species are determined by XPS measurements. The peak positions in all of the XPS spectra are calibrated with $\mathrm{C}$
$1 \mathrm{~s}$ at $284.6 \mathrm{eV}$. Figure 3(A) shows the XPS spectrum of GO- $\mathrm{Ag}_{3} \mathrm{PO}_{4} @ \mathrm{AgCl}-0.5$, as seen, the survey contains carbon, oxygen, phosphorous, silver and chloride elements. The XPS peaks of $\mathrm{Ag} 3 \mathrm{~d}$ are shown in Figure 3(B) the peak at 367.5 and $373.5 \mathrm{eV}$ are attributed to $\mathrm{Ag} 3 \mathrm{~d}_{5 / 2}$ and $\mathrm{Ag} 3 \mathrm{~d}_{3 / 2}$ respectively, 
confirming the presence of $\mathrm{Ag}^{+}$on the as-prepared composite [34]. As in Figure 3(C) the peaks with binding energies 184.6, 186.1 and $188.1 \mathrm{eV}$ are corresponded to the following functional groups $\mathrm{C}-\mathrm{C}$ in aromatic rings, $\mathrm{C}-\mathrm{O}$ of epoxy and alkoxy groups and $\mathrm{O}-\mathrm{C}=\mathrm{O}$ of the carbonyl group, respectively [35]. The high resolution XPS spectrum in Figure 3(D) shows the peaks with binding energies of 530.6 and $532.6 \mathrm{eV}$ which are assigned to the $\mathrm{O} 1 \mathrm{~s}$ peaks, which correspond to the oxygen element of the $\mathrm{Ag}_{3} \mathrm{PO}_{4}$ crystal lattice and the hydroxyl or carboxyl groups on the surface of GO [36]. As in Figure 3(E) the $\mathrm{Cl} 2 \mathrm{p}$ is deconvoluted into two peaks at 197.5 and 199.1 $\mathrm{eV}$ [37]. P 2p spectra shows peak at $133.3 \mathrm{eV}$ as in Figure 3(F), which may attributed to the $\mathrm{P}^{5+}$ in $\mathrm{PO}_{4}{ }^{3-}$ [34]. The XPS results further confirmed that the $\mathrm{GO}-\mathrm{Ag}_{3} \mathrm{PO}_{4} @ \mathrm{AgCl}-0.5$ is successfully fabricated.
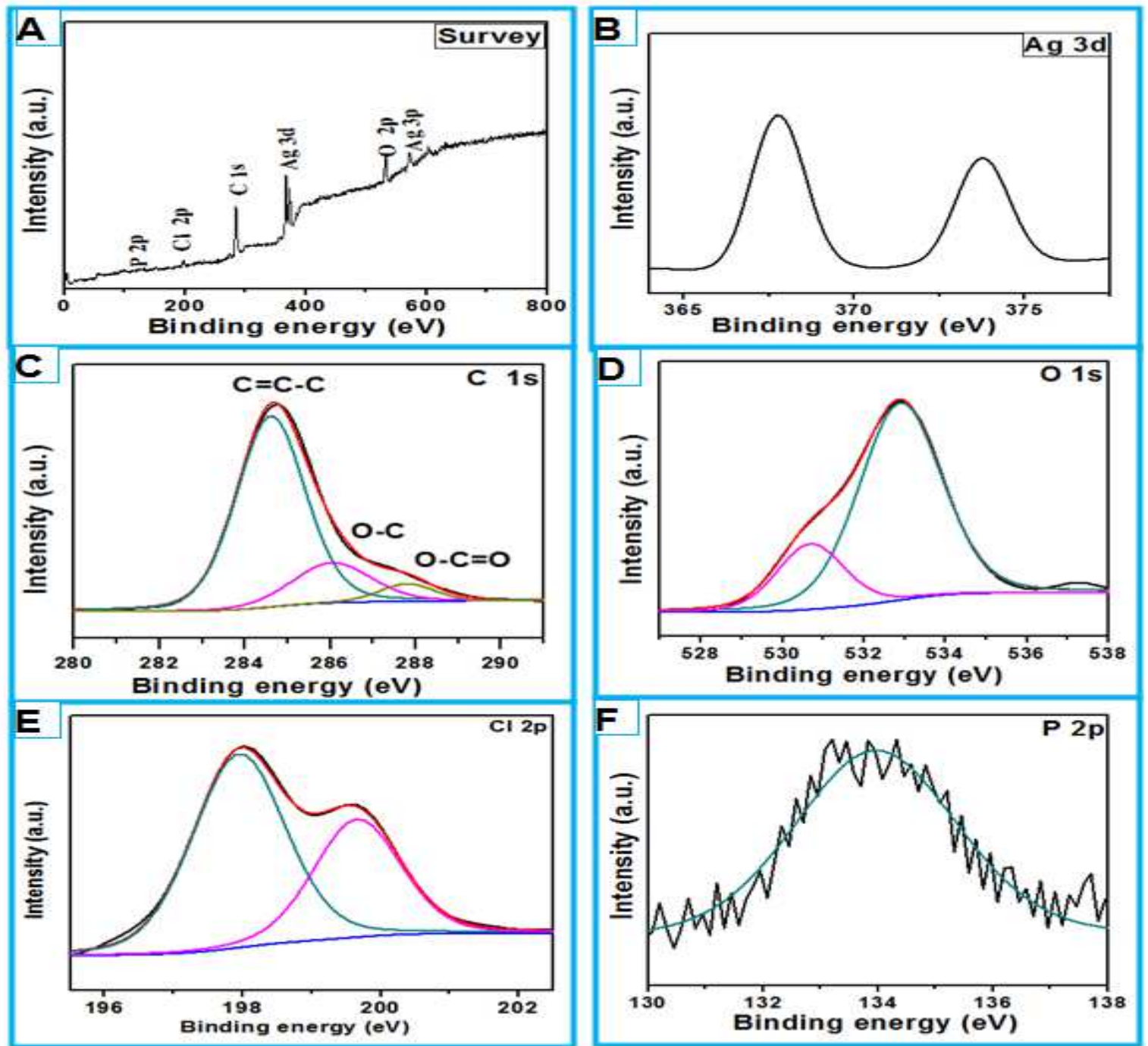

Figure 3. XPS spectra of the GO-Ag $\mathrm{PO}_{4} @$ @AgCl-0.5 composite: (A) XPS survey spectrum, (B) high-resolution Ag 3d spectrum, (C) high-resolution C 1s spectra, (d) high-resolution $O$ 1s spectrum, (E) high-resolution Cl $2 p$ spectrum, (F) high-resolution $P 2 p$ spectrum.

\subsection{UV-Vis Diffuse Reflectance Spectra Analysis}

UV-Vis diffuse reflectance measurements of $\mathrm{Ag}_{3} \mathrm{PO}_{4}$, $\mathrm{Ag}_{3} \mathrm{PO}_{4} @ \mathrm{AgCl}$ and $\mathrm{GO}-\mathrm{Ag}_{3} \mathrm{PO}_{4} @ \mathrm{AgCl}-0.5$ composites are shown in Figure 4(A), it can be seen clearly that $\mathrm{Ag}_{3} \mathrm{PO}_{4}$ can absorb visible light around $530 \mathrm{~nm}$ [38]. In the GO$\mathrm{Ag}_{3} \mathrm{PO}_{4} @ \mathrm{AgCl}-0.5$ composite spectra small shift in the band edge position is observed compared with pure $\mathrm{Ag}_{3} \mathrm{PO}_{4}$ and $\mathrm{Ag}_{3} \mathrm{PO}_{4} @ \mathrm{AgCl}$, moreover the absorbance higher than $500 \mathrm{~nm}$ is enhanced. Suggesting that GO- $\mathrm{Ag}_{3} \mathrm{PO}_{4} @ \mathrm{AgCl}-0.5$ photocatalyst may has higher efficiency to absorb visible light. In addition, the recombination rate of the electron-hole pair is successfully reduced.

\subsection{PL Spectra Analysis}

The transfer and recombination processes of the photogenerated electron-hole pairs can be detected by the PL spectra of the synthesized photocatalysts. The lower PL intensity is the less recombination rate of the photogenerated charge carriers [39]. Thus the better photocatalytic activity in the photocatalytic reaction. As in Figure 4(B), the PL spectra of $\mathrm{GO}-\mathrm{Ag}_{3} \mathrm{PO}_{4} @ \mathrm{AgCl}-0.5$ and $\mathrm{Ag}_{3} \mathrm{PO}_{4} @ \mathrm{AgCl}$ are show strong peak around $400 \mathrm{~nm}$ which attributed to charge recombination of $\mathrm{O} 2 \mathrm{p}$ orbitals and $\mathrm{d}$ orbital of $\mathrm{Ag}^{+}$for $\mathrm{Ag}_{3} \mathrm{PO}_{4}[25]$ and weak peak at $530 \mathrm{~nm}$ is attributed to $\mathrm{Ag}_{3} \mathrm{PO}_{4}$. 
Peak at around $474 \mathrm{~nm}$ is assigned to $\mathrm{AgCl}$. The graphene-based photocatalyst is exhibited lower peak intensity of PL spectra than that of $\mathrm{Ag}_{3} \mathrm{PO}_{4} @ \mathrm{AgCl}$, indicating that the migration of the photogenerated species between

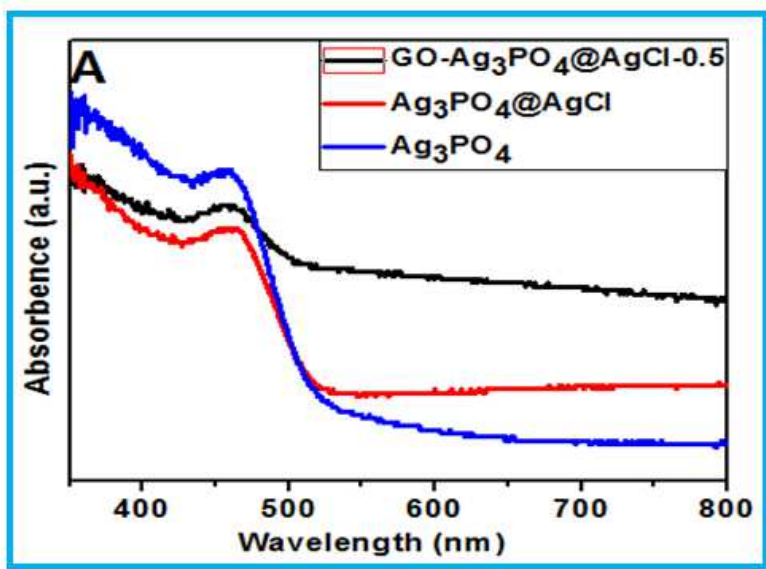

$\mathrm{AgCl}, \mathrm{Ag}_{3} \mathrm{PO}_{4}$ and graphene sheets. Thus, confirming the effectiveness of the GO- $\mathrm{Ag}_{3} \mathrm{PO}_{4} @ \mathrm{AgCl}-0.5$ composite for the separation of the photogenerated electron-hole pairs.

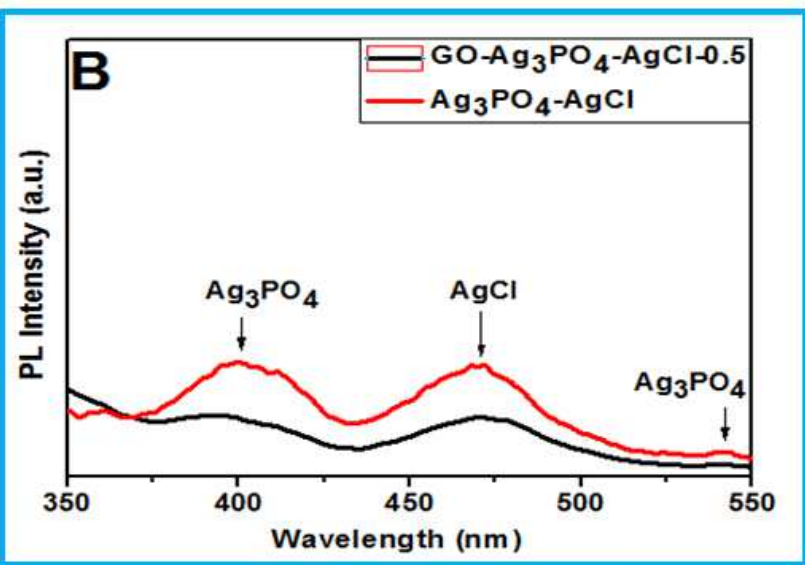

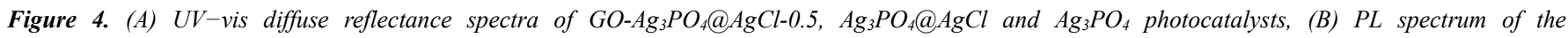
GO-Ag $\mathrm{PO}_{4} @ \mathrm{AgCl}-0.5$ and $\mathrm{Ag}_{3} \mathrm{PO}_{4} @ \mathrm{AgCl}$ photocatalysts.

\subsection{Study of Photocatalytic Activity}

For the evaluation of the photocatalytic performance of the synthesized composites for the degradation of organic dyes under simulated sunlight, $\mathrm{RhB}$ is used as representative sample. Different GO- $\mathrm{Ag}_{3} \mathrm{PO}_{4} @ \mathrm{AgCl}$ composites with different $\mathrm{AgCl}$ contents are used for the degradation of $\mathrm{RhB}$ under simulated sunlight irradiation to investigate the optimal $\mathrm{Cl} / \mathrm{P}$ molar ratio in the photocatalytic process. The results reveal that $\mathrm{GO}-\mathrm{Ag}_{3} \mathrm{PO}_{4} @ \mathrm{AgCl}-0.5$ is presented the highest photocatalytic performance (Figure 5). As the $\mathrm{Cl} / \mathrm{P}$ ratio increased from 0.5 to 0.7 , a decrease on the photocatalytic activity of $\mathrm{GO}-\mathrm{Ag}_{3} \mathrm{PO}_{4} @ \mathrm{AgCl}$ is observed. This may be due to more $\mathrm{AgCl}$ particles are formed on the surface of $\mathrm{Ag}_{3} \mathrm{PO}_{4}$ which decrease the light absorbed by $\mathrm{Ag}_{3} \mathrm{PO}_{4}$. Moreover, the dye may have been isolated from the direct contact with the surface of $\mathrm{Ag}_{3} \mathrm{PO}_{4}$.

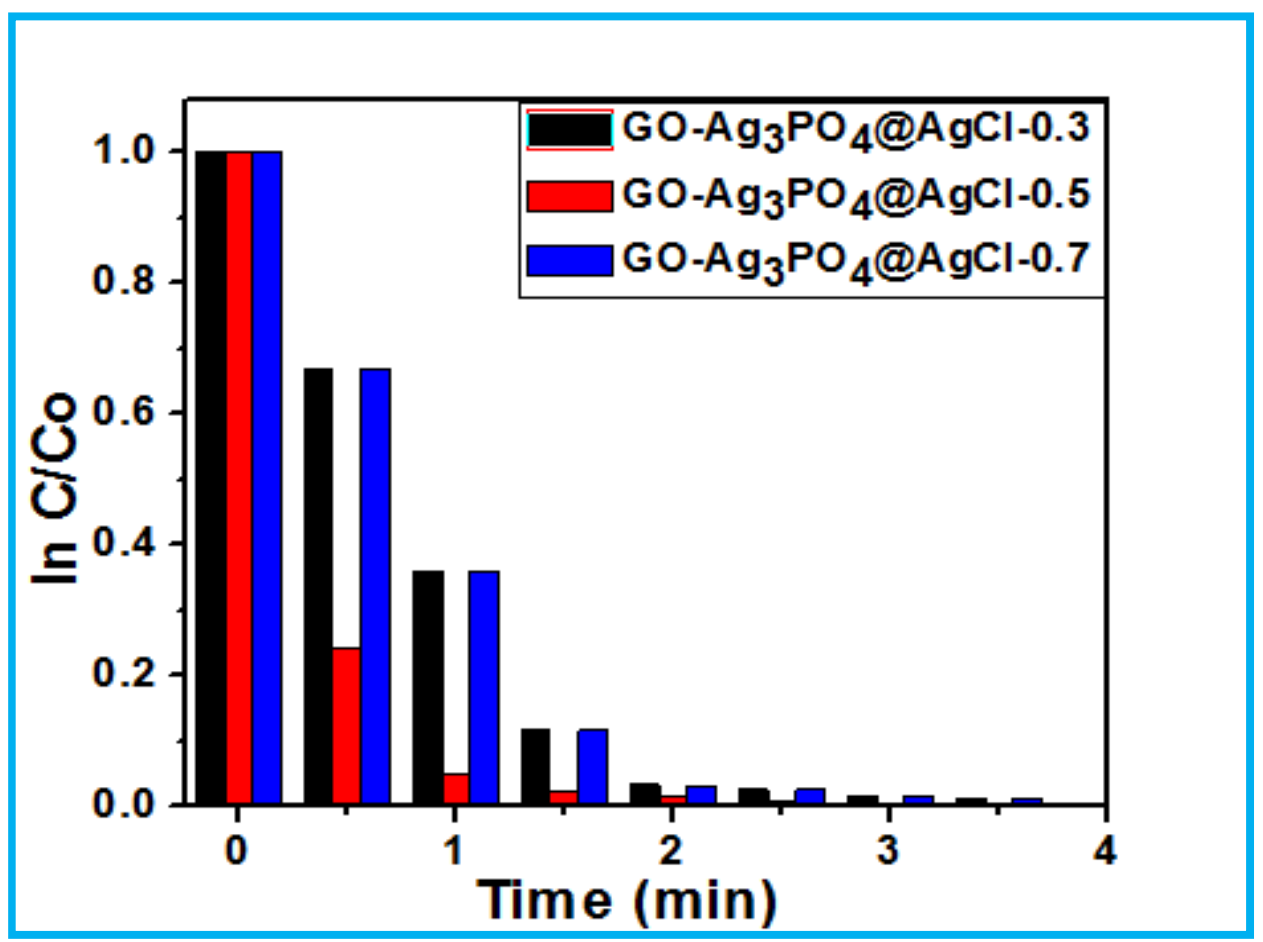

Figure 5. Absorption changes of RhB solution under simulated sunlight irradiation in the presence of $\mathrm{GO}-\mathrm{Ag}_{3} \mathrm{PO}_{4} @ \mathrm{AgCl}-0.3, \mathrm{GO}-\mathrm{Ag} 3 \mathrm{PO} \mathrm{O}_{4} @ \mathrm{AgCl}-0.5$ and $\mathrm{GO}-\mathrm{Ag}_{3} \mathrm{PO}_{4} @ \mathrm{AgCl}-0.7$.

Figure 6 shows the Photodegradation of $\mathrm{RhB}$ as a function of irradiation time over different photocatalysts under 
simulated sunlight. The photodegradation of the $\mathrm{RhB}$ under light irradiation in the absence of any of the photocatalysts and in the dark condition $(\mathrm{RhB}$ and photocatalyst without light irradiation) is neglected. All the synthesized photocatalysts exhibited excellent photocatalytic activities toward the degradation of $\mathrm{RhB}$. Among them, GO- $\mathrm{Ag}_{3} \mathrm{PO}_{4} @ \mathrm{AgCl}-0.5$ is exhibited the highest photocatalytic activity than the other photocatalysts near by $100 \%$ in $1.5 \mathrm{~min} . \mathrm{Ag}_{3} \mathrm{PO}_{4} @ \mathrm{AgCl}$ and $\mathrm{Ag}_{3} \mathrm{PO}_{4}$ are needed $3 \mathrm{~min}$ to exhibit degradation efficiency nearly $100 \%$ and $80 \%$ respectively. The enhanced photocatalytic activity is due to the efficient charge separation in $\mathrm{GO}-\mathrm{Ag}_{3} \mathrm{PO}_{4} @ \mathrm{AgCl}-0.5$ catalyst system.

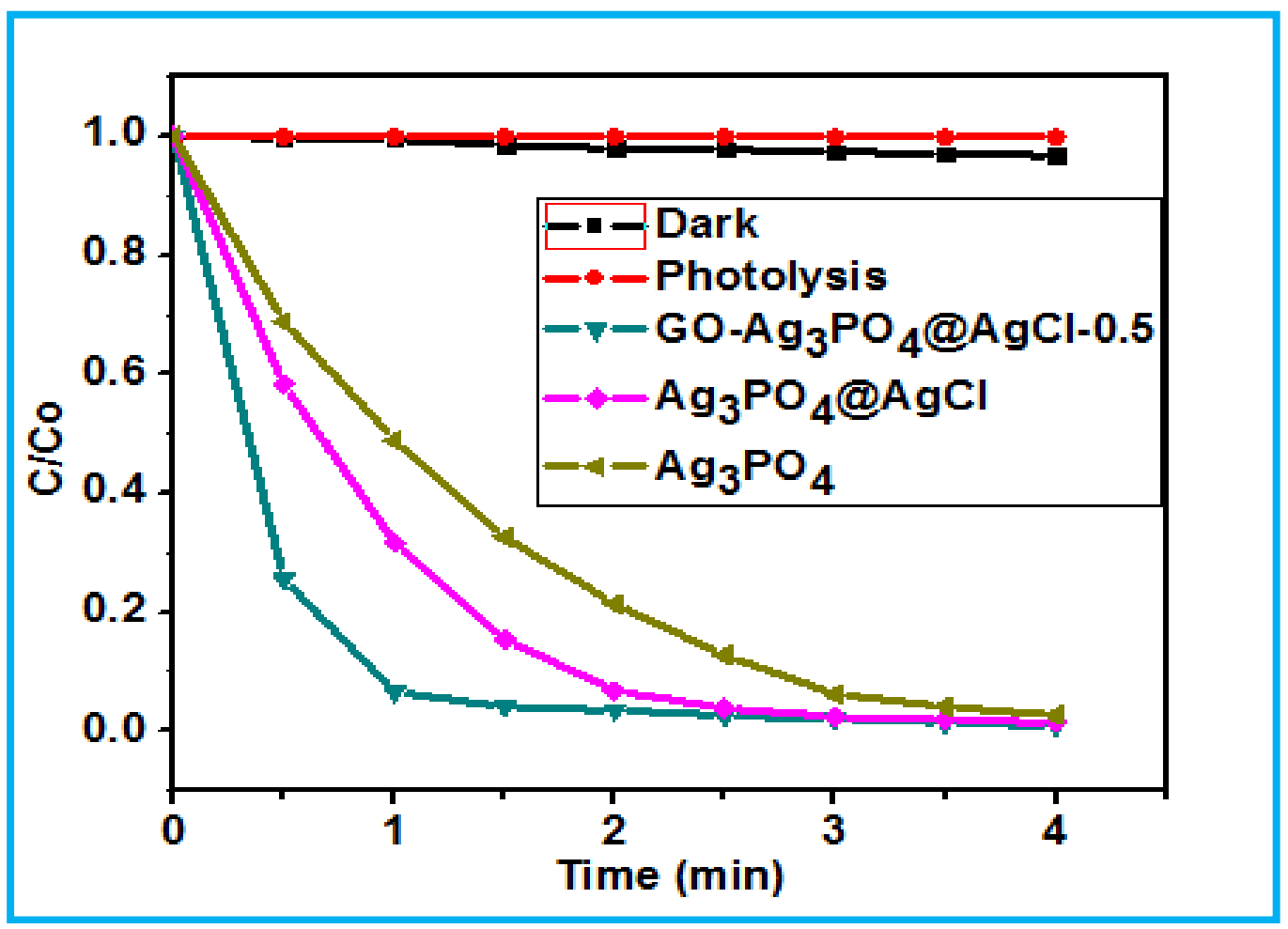

Figure 6. Comparison of photocatalytic activity of synthesized photocatalysts for degradation of RhB under simulated sunlight irradiation.

\subsection{Kinetic Study}

In order to investigate the kinetic behavior of the synthesized photocatalysts on the degradation of $\mathrm{RhB}$ under simulated sunlight irradiation, $\ln (\mathrm{C} / \mathrm{Co})$ for $\mathrm{RhB}$ is plotted versus irradiation time according to the following first-order kinetic model:

$$
\ln (\mathrm{C} / \mathrm{Co})=-\mathrm{kt}
$$

Where $\mathrm{k}$ is the degradation rate constant, $\mathrm{Co}$ and $\mathrm{C}$ the initial concentration and the concentration at different irradiation time $\mathrm{t}$ of the organic dye respectively. From the result presented in Figure 7, the disappearance of RhB over the different synthesized photocatalysts under simulated sunlight irradiation is shown to fit a pseudo first order kinetics pattern, with $\mathrm{R}^{2}$ of $0.9849,0.9683$ and 0.9845 for GO-Ag $\mathrm{PO}_{4} @ \mathrm{AgCl}-0.5, \quad \mathrm{Ag}_{3} \mathrm{PO}_{4} @ \mathrm{AgCl}$ and $\mathrm{Ag}_{3} \mathrm{PO}_{4}$ respectively, and degradation rate constants of 2.062, 1.091 and $0.8855 \mathrm{~min}^{-1}$ for GO- $\mathrm{Ag}_{3} \mathrm{PO}_{4} @ \mathrm{AgCl}-0.5, \mathrm{Ag}_{3} \mathrm{PO}_{4} @ \mathrm{AgCl}$ and $\mathrm{Ag}_{3} \mathrm{PO}_{4}$ respectively. From the values of $\mathrm{k}_{\text {obs }}$ and $\mathrm{R}^{2}$ shown in Table 1 , it is concluded that the degradation of RhB over the as-synthesized GO- $\mathrm{Ag}_{3} \mathrm{PO}_{4} @ \mathrm{AgCl}-0.5$ under simulated sunlight irradiation is faster than that over $\mathrm{Ag}_{3} \mathrm{PO}_{4} @ \mathrm{AgCl}$ and $\mathrm{Ag}_{3} \mathrm{PO}_{4}$, confirming that $\mathrm{GO}$ has effectively enhanced the charge separation in the GO- $\mathrm{Ag}_{3} \mathrm{PO}_{4} @ \mathrm{AgCl}-0.5$ composite compared with
$\mathrm{Ag}_{3} \mathrm{PO}_{4} @ \mathrm{AgCl}$.

Table 1. Degradation rate constants of RhB over the different synthesized photocatalysts under simulated sunlight irradiation.

\begin{tabular}{lll}
\hline Photocatalysis & $\mathbf{k}_{\text {obs }}$ & $\mathbf{R}^{\mathbf{2}}$ \\
\hline $\mathrm{GO}-\mathrm{Ag}_{3} \mathrm{PO}_{4} @ \mathrm{AgCl}-0.5$ & 2.062 & 0.9849 \\
$\mathrm{Ag}_{3} \mathrm{PO}_{4} @ \mathrm{AgCl}$ & 1.091 & 0.9683 \\
$\mathrm{Ag}_{3} \mathrm{PO}_{4}$ & 0.8855 & 0.9845 \\
\hline
\end{tabular}

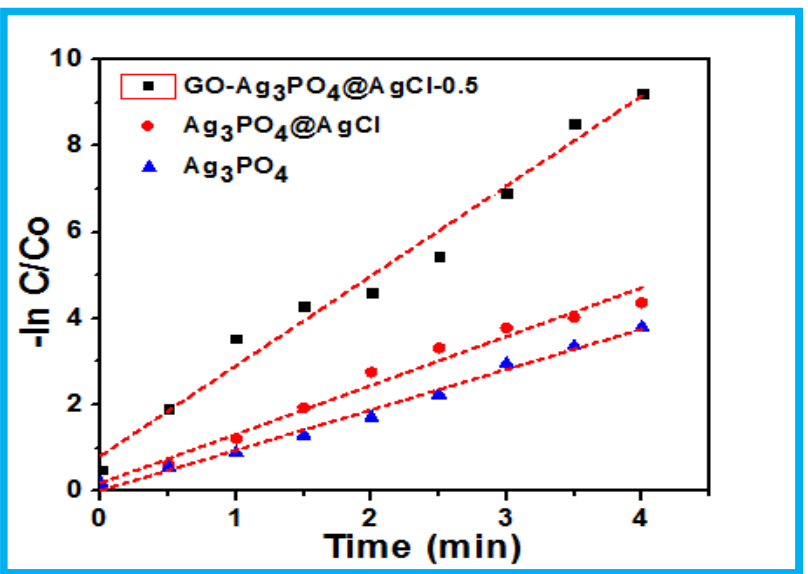

Figure 7. Comparison of photocatalytic activity of synthesized photocatalysts for degradation of $R h B$. 


\subsection{Stability Study}

The stability and recyclability of $\mathrm{GO}-\mathrm{Ag}_{3} \mathrm{PO}_{4} @ \mathrm{AgCl}-0.5$ are evaluated by additional experiments to degrade $\mathrm{RhB}$ under simulated sunlight irradiation cycled for three times [Figure

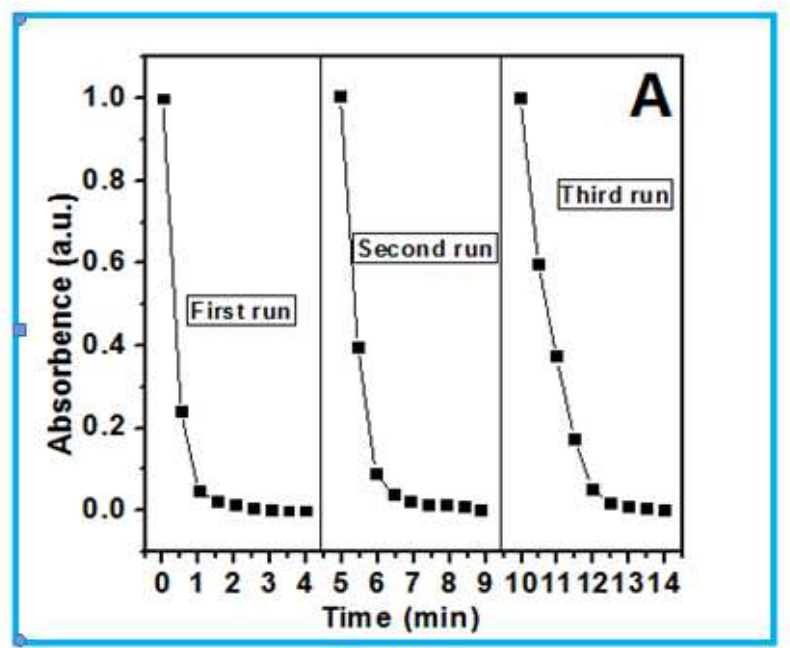

Figure 8. (A) Stability study on the photocatalytic degradation of RhB solution over GO-Ag $\mathrm{P}_{3} \mathrm{OO}_{4} @ \mathrm{AgCl}-0.5$ composite under simulated sunlight irradiation, and (B) Effect of reactive species on the photocatalytic degradation process of $\mathrm{RhB}$ solution over $\mathrm{GO}-\mathrm{Ag}_{3} \mathrm{PO} \mathrm{O}_{4} @ \mathrm{AgCl}-0.5$.

\subsection{Photocatalytic Mechanism}

To investigate the reactive oxygen species in the photocatalytic degradation process, in this study the expected active species such as $\mathrm{h}^{+}$, $\mathrm{OH}$ or ${ }^{\circ} \mathrm{O}_{2}^{-}$effects on the photocatalytic process is examined by using BZQ as ${ }^{\circ} \mathrm{O}_{2}{ }^{-}$ scavenger, $\mathrm{Na}_{2}$-EDTA as $\mathrm{h}^{+}$scavenger and tert-butanol as ${ }^{\circ} \mathrm{OH}$ scavenger. The experimental results [Figure 8(B)] have indicated that the addition of BZQ to the photocatalytic system has decreased the photocatalytic activity of GO- $\mathrm{Ag}_{3} \mathrm{PO}_{4} @ \mathrm{AgCl}-0.5$ for the degradation of $\mathrm{RhB}$ in $1.5 \mathrm{~min}$

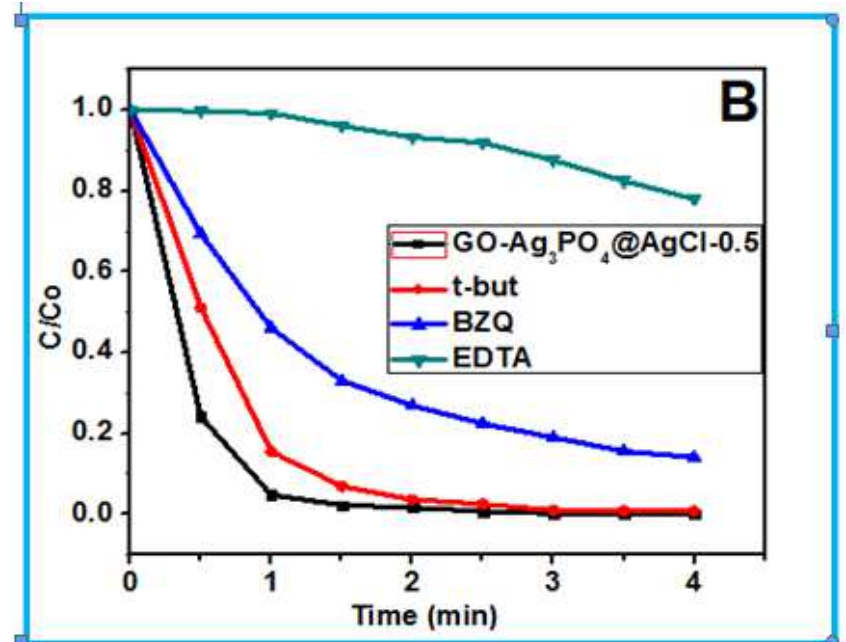

8(A)]. It can be observed that $\mathrm{GO}-\mathrm{Ag}_{3} \mathrm{PO}_{4} @ \mathrm{AgCl}-0.5$ have good stability for the degradation of $\mathrm{RhB}$ under sunlight irradiation during three cycles.

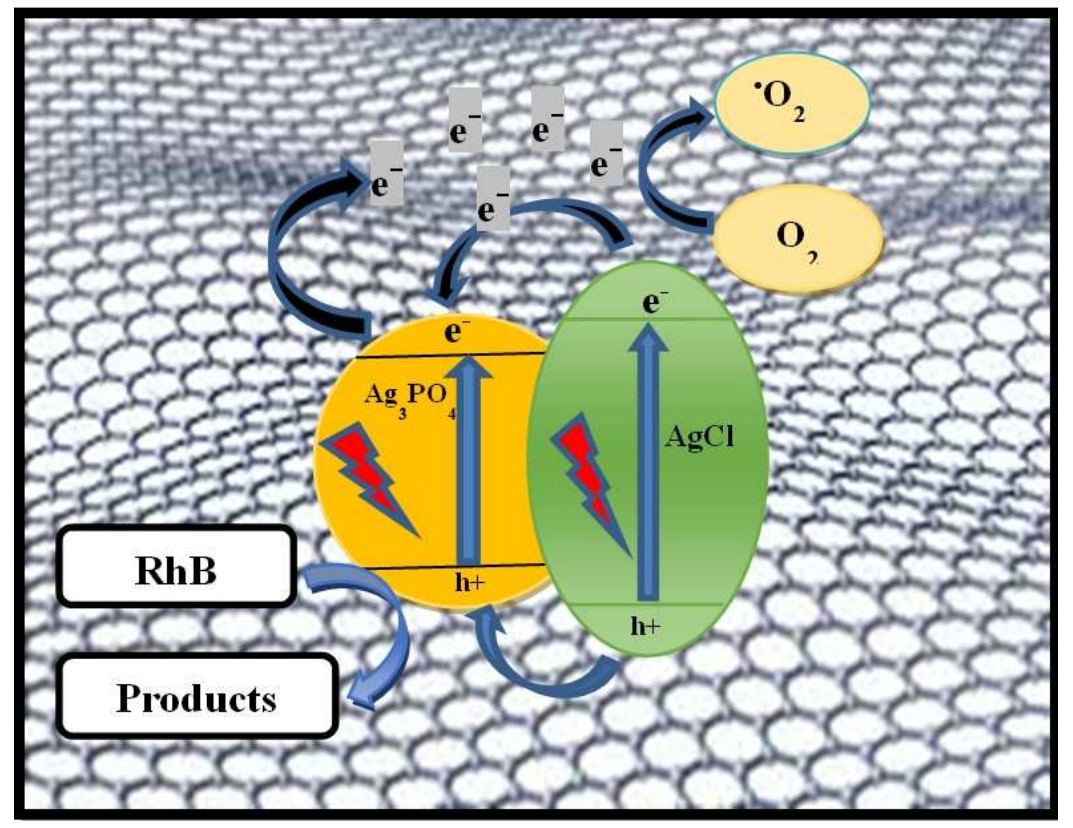

Figure 9. Proposed mechanism of enhanced photocatalytic activity for the $\mathrm{GO}-\mathrm{Ag} \mathrm{PO}_{4} @ \mathrm{AgCl}$.

Based on the above results, the reaction mechanism can be proposed as seen in Figure 9, when GO- $\mathrm{Ag}_{3} \mathrm{PO}_{4} @ \mathrm{AgCl}-0.5$ 
composite is exposed to simulated sunlight the electrons in the valence band of $\mathrm{AgCl}$ could transfer to its conductive band (CB) leaving holes behind, then transfer to the $\mathrm{CB}$ of $\mathrm{Ag}_{3} \mathrm{PO}_{4}$, afterwards, the photogenerated electrons on the conductive band of $\mathrm{Ag}_{3} \mathrm{PO}_{4}$ could efficiently transfer to the GO sheets, thus enhance the charge separation on the surface of $\mathrm{Ag}_{3} \mathrm{PO}_{4}$, resulting on the improvement of the photocatalytic activity. The electrons on the GO reduce the molecular oxygen to form super-oxide radicals ${ }^{\circ} \mathrm{O}_{2}{ }^{-}$which further degrade $\mathrm{RhB}$. On the other hand, the holes on the valence band (VB) of $\mathrm{AgCl}$ could transfer to the $\mathrm{VB}$ of $\mathrm{Ag}_{3} \mathrm{PO}_{4}$. As reported previously [34], the photogenerated holes on $\mathrm{Ag}_{3} \mathrm{PO}_{4}$ could not oxidize $\mathrm{H}_{2} \mathrm{O}$ into ${ }^{\circ} \mathrm{OH}$ radicals. Because the valence band edge potential of $\mathrm{Ag}_{3} \mathrm{PO}_{4}(2.64 \mathrm{~V})$ is less positive than the standard redox potential of ${ }^{\circ} \mathrm{OH} / \mathrm{H}_{2} \mathrm{O} \quad(2.72 \mathrm{~V}) \quad[40,41]$. Thus the photogenerated holes on the VB of $\mathrm{Ag}_{3} \mathrm{PO}_{4}$ could directly react with $\mathrm{RhB}$.

From the results of FT-IR, XRD, SEM, XPS, UV-Vis diffuse reflectance, PL and the photocatalytic degradation process mentioned above, the enhancement of the photocatalytic activity of $\mathrm{GO}-\mathrm{Ag}_{3} \mathrm{PO}_{4} @ \mathrm{AgCl}-0.5$ over $\mathrm{Ag}_{3} \mathrm{PO}_{4} @ \mathrm{AgCl}$ may be due to the efficiency of GO for the separation and transformation of the photogenerated electron-hole pairs. Also, GO is become a p-type semiconductor because of possessing a large amount of oxygen bonding on the $\mathrm{sp}^{3}$ hybridized carbon, so, its conduction band is the antibonding $\pi^{*}$ orbital and the $O 2 p$ orbital its valence band [42]. Thus a $\mathrm{p} / \mathrm{n}$ heterojunction can be form when $\mathrm{GO}$ is combined with $\mathrm{Ag}_{3} \mathrm{PO}_{4}$ (n-type semiconductor), resulting on more efficient charge separation. Moreover, the electrostatic interaction between the negatively charged GO and positively charged $\mathrm{RhB}$ let the cationic dye to concentrate on the surface of the GO sheets, thus accelerate the interaction between the photogenerated species and the $\mathrm{RhB}$, which promote the degradation process [43].

\section{Conclusion}

In summary, a GO- $\mathrm{Ag}_{3} \mathrm{PO}_{4} @ \mathrm{AgCl}$ composite with high simulated sunlight photocatalytic performance was successfully prepared through a facile, environmentally friendly, and economical in-situ ion-exchange method. GO- $\mathrm{Ag}_{3} \mathrm{PO}_{4} @ \mathrm{AgCl}-0.5$ exhibited the highest photocatalytic activity for the degradation of $\mathrm{RhB}$ under simulated sunlight irradiation compared with $\mathrm{Ag}_{3} \mathrm{PO}_{4} @ \mathrm{AgCl}$ and pure $\mathrm{Ag}_{3} \mathrm{PO}_{4}$. GO sheets with excellent electron accepting and transporting properties effectively enhanced the photocatalytic activity of $\mathrm{Ag}_{3} \mathrm{PO}_{4} @ \mathrm{AgCl}$. Moreover, the photocatalytic mechanism investigations demonstrated that $\mathrm{h}^{+}$and ${ }^{\circ} \mathrm{O}_{2}{ }^{-}$played a key role in the degradation of $\mathrm{RhB}$ over GO- $\mathrm{Ag}_{3} \mathrm{PO}_{4} @ \mathrm{AgCl}-0.5$ composite under simulated sunlight irradiation. The disappearance of the $\mathrm{RhB}$ was showed to fit a pseudo first order kinetic pattern. The resulting GO- $\mathrm{Ag}_{3} \mathrm{PO}_{4} @ \mathrm{AgCl}-0.5$ composite may be a promising efficient photocatalyst for the degradation of organic pollutants in the industrial and engineering field.

\section{Acknowledgments}

This work was supported by the Natural Science Foundation of China (Grant Nos. 21327005, 21175108); the Program for Chang Jiang Scholars and Innovative Research. Team, Ministry of Education, China. (Grant No. IRT1 283); the Program for Innovative Research Group of Gansu Province, China (Grant No. 1210RJIA001).

\section{References}

[1] Kubacka, M.F. Garcia, G. Colon, Chemical Reviews, 2012, 112, $1555-1614$.

[2] H. Tong, S.X. Ouyang, Y.P. Bi, N. Umezawa, M. Oshikiri, J. Ye, Advanced Materials, 2012, 24, 229-251.

[3] Ratna1, B.S. Padhi, Environmental Sciences, 2012, 3, 940-955.

[4] Y.P. Bi, S.X. Ouyang, N. Umezawa, J.Y. Cao, J. H. Ye, American Chemical Society, 2011, 133, 6490-6492.

[5] Y.P. Bi, H.Y. Hu, S.X. Ouyang, G.X. Lu, J.Y. Cao, J.H. Ye, Chemical Communications, 2012, 48, 3748-3750.

[6] W.G. Wang, B. Cheng, J.G. Yu, G. Liu, W.H. Fan, Chemistry An Asian J., 2012, 7, 1902-1908.

[7] H. Wang, L. He, L.H. Wang, P.F. Hu, L. Guo, X.D. Han, J.H. Li, CrystEngComm, 2014, 14, 8342-8344.

[8] K. Santosh, T. Surendar, B. Arabind, S. Vishnu, Materials Chemistry A, 2013, 1, 5333-5340.

[9] Y. P. Bi, H. Y.Hu, S.X. Ouyang, Z.B. Jiao, G.X. Lu, J.H. Ye, Chemistry - A European J., 2012, 18, 14272-14275.

[10] W.F. Yao, B. Zhang, C.P. Huang, C. Ma, X.L. Song, Q.J. Xu, Materials Chemistry, 2012, 22, 4050-4055.

[11] W. Liu, M. L. Wang, C.X. Xu, S.F. Chen, X.L. Fu, Materials Research Bulletin, 2013, 48, 106-113.

[12] L.L. Zhang, H.C. Zhang, H. Huang, Y. Liu, Z.H. Kang, Chemistry, 2012, 36 1541-1544.

[13] Y. Bi, S. Ouyang, J. Cao, J. Ye, Physical Chemistry Chemical Physics, 2011, 13, 10071-10075.

[14] Q. J. Xiang, J.G. Yu, M. Jaroniec, Chemical Society Reviews, 2012, 41, 782-796.

[15] X.Q. An, J.C. Yu, RSC Advances, 2011, 1, 1426-1434.

[16] B.J. Jiang, C.G. Tiang, Q.J. Pan, Z. Jiang, J.Q. Wang, W.S. Yan, H.G. Fu, Physical Chemistry C, 2011, 115, 23718-23725.

[17] H. Zhang, X.F. Fan, X. Quan, S. Chen, H.T. Yu, Environmental Science and Technology, 2011, 45, 5731-5736.

[18] G.D. Chen, M. Sun, Q. Wei, Y.F. Zhang, B.C. Zhu, B. Du, Hazardous Material, 2013, 244, 86-93.

[19] A. Yanhui, W. Peifang, W. Chao, H. Jun, Q. Jin, Applied Surface Science, 2013, 271, 265-270.

[20] H. Guangyu, Q. Maogong, S. Xiaoqiang, C. Qun, W. Xin, C. Haiqun, Powder Technology, 2013, 246, 278-283. 
[21] B.J. Jiang, Y.H. Wang, J.Q. Wang, C.G. Tiang, W.J. Li, Q.M. Feng, Q.J. Pan, H.G. Fu, ChemCatChem, 2013, 5, 1359-1367.

[22] W.S. Hummers, R.E. Offeman, American Chemical Society, $1958,80,1339-1339$.

[23] M.C. Yin, Z.S. Li, J.H. Kou, Z.G. Zou, Environmental Science and Technology, 2009, 43 8361-8366.

[24] P.Y. Dong, Y.H. Wang, B.C. Cao, S.Y. Xin, L.N. Guo, J. Zhang, F. H. Li, Applied Catalysis B, 2013, 132, 45-53.

[25] Q.H. Liang, Y. Shi, W.J. Ma, Z. Li, X.M. Yang, Physical Chemistry, Chemical Physics, 2012, 14, 15657-15665.

[26] H. Tang, K. Prasad, R. Sanjinès, P.E. Schmid, F. Lévy, Applied Physics, 1994, 75, 2042-2047.

[27] H.N. Ng, C. Calvo, R. Faggiani, Acta Crystallographica Section B: Structural Science, 1978, 34, 898-899.

[28] A. Pongsaton, S. Sumetha, Advanced Powder Technology, 2014, 25, 1026-1030.

[29] V. Gopinath, S. Priyadarshini, N.M. Priyadharsshini, K. Pandian, P. Velusamy, Materials Letters, 2013, 91, 224-227.

[30] X.F. Yang, H.Y. Cui, Y. Li, J.L. Qin, R.X. Zhang, H. Tang, American Chemical Society Catalysis, 2013, 3, 363-369.

[31] J. Liu, H. Bai, Y. Wang, Z. Liu, X. Zhang, D.D. Sun, Advanced Functional Materials, 2010, 20, 4175-4181.

[32] X. Gu, Sh.Zhang, B. Wang, Y. Qiang, Optoelectronics Letters, 2014, 10, 219-222.
[33] M. Zhu, P. Chen, M. Liu, American Chemical Society Nano, 2011, 5, 4529-4536.

[34] M. Ge, N. Zhu, Y.P. Zhao, J. Li, L. Liu, Industrial \& Engineering Chemistry Research, 2012, 51, 5167-5173.

[35] W.G. Wang, J.G. Yu, Q.J. Xiang, B. Cheng, Applied Catalysis B, 2012, 119, 109-116.

[36] Z. Hu, Y.D. Huang, S.F. Sun, W.C. Guan, Y.H. Yao, P.Y. Tang, C. Li, Carbon, 2012, 50, 994-1004.

[37] M. Zhu, P. Chen, M. Liu, Material Chemistry, 2011, 21, 16413-16419.

[38] A.V. Murugan, T. Muraliganth, A. Manthiram, Chemistry of Materials, 2009, 21, 5004-5006.

[39] Z.G. Yi, N. Kikugawa, T. Kako, H. Stuart-Williams, H. Yang, J.Y. Cao, W. J. Luo, Z.S. Li, Y. Liu, R.L. Withers, Nature Materials, 2010, 9, 559-564.

[40] X.G. Ma, B. Lu, D. Li, R. Shi, C.S. Pan, Y.F. Zhu, Physical Chemistry C, 2011, 115, 4680-4687.

[41] J.Cao, B.D. Luo, H.L. Lin, B.Y. Xu, S.F. Chen, Hazardous Material, 2012, 217, 107-115.

[42] T.F. Yeh, J.M. Syu, C. Cheng, T.H. Chang, H.S. Teng, Advanced Functional Material, 2010, 20, 2255-2262.

[43] S. Bai, X. Shen, H. Lv, G. Zhu, C. Bao, Y. Shan, Colloid and Interface Science, 2013, 405, 1-9. 